\title{
Notices
}

\section{The Society of Experimental Psychologists \\ Elections to Membership}

The Society of Experimental Psychologists, which was founded in 1929 and which presently comprises about 155 members and fellows, elects some five members each year from among distinguished North American experimental psychologists. The following were elected members of the Society at its 1983 meeting at the University of California, San Diego:

\author{
J. Anthony Deutsch, University of California, San Diego \\ Norma Graham, Columbia University \\ Irwin Pollack, University of Michigan \\ John A. Swets, Bolt Beranek and Newman, Cambridge, Massachusetts
}

The following were elected members at the Society's 1984 meeting at the University of Toronto:

Donald E. Broadbent, University of Oxford

Herbert H. Clark, Stanford University

Paul Rozin, University of Pennsylvania

Edward E. Smith, Bolt Beranek and Newman, Cambridge, Massachusetts

Wayne A. Wickelgren, University of Oregon

\section{The Society of Experimental Psychologists \\ The Howard Crosby Warren Medal}

The Howard Crosby Warren Medal of The Society of Experimental Psychologists was awarded recently to the following individuals:

In 1983, to Richard Held of the Massachusetts Institute of Technology, for his meticulous and imaginative research on the genesis of spatial vision and visually guided behavior. His varied approaches have included controlled rearing experiments with cats and monkeys, adaptation to rearrangement in human adults, and now developmental studies with human infants.

In 1984, to Eric R. Kandel of Columbia University, for his pioneering studies which, by integrating the fundamental work on habituation, sensitization, and conditioning and the techniques of neurophysiology and neurochemistry, have elucidated the cellular mechanisms of associative learning. 